\title{
Thorwaldt's Cyst: Management by Combined Endoscopic Approach and Literature Review
}

\author{
Tawfeeq E*, Dashti G, Sheikh MA and Bastaki JM \\ Department of Otolaryngology, Zain Hospital of Otolaryngology, Kuwait
}

*Corresponding author: Essa Tawfeeq, Department of Otolaryngology, Zain Hospital of Otolaryngology, Kuwait, Tel: +965 99873362; Email: essatwfq@gmail.com

\section{Case Report}

Volume 6 Issue 2

Received Date: September 02, 2021

Published Date: September 15, 2021

DOI: $10.23880 /$ ooaj-16000222

\section{Abstract}

Thornwaldt cysts occur in the midline bursa of the nasopharynx above the upper border of the superior constrictor muscle. They represent a communication between notochord remnants and the pharyngeal endoderm. It is usually asymptomatic unless an infection or obstruction occurs, then, a Thornwaldt's cyst might develop. It is relatively uncommon, with a prevalence rate of $0.2 \%$ to $4 \%$. Due to its nonspecific symptoms, physician often misdiagnose thornwaldt cyst. It is usually diagnosed as an incidental finding on MRI. Surgical excision is the definitive treatment. This paper describes a case of thornwaldt cyst in a 39 years old gentleman presented with neck stiffness. It also includes a literature review that aids in the clinical suspicion, prevalence, diagnosis, and treatment of thornwald cyst.

Keywords: Thornwaldt; Tornwaldt; Cyst; Nasopharyngeal; Combined endoscopic approach

Abbreviations: CT: Computed tomography; MRI: Magnetic Resonance Imaging.

\section{Introduction}

Thornwaldt's bursa, also known as nasopharyngeal bursa, is a recess in the midline of the nasopharynx that is produced by persistent notochord remnants. If its opening becomes obstructed, possibly due to infection or a complication from adenoidectomy, a Thornwaldt's cyst might develop [1]. It is usually small and accidentally diagnosed on MRI. Large sized cyst may present with nasal, ear or cervical symptoms. Recurrent nasopharyngeal infection and trauma are common etiological factor. Surgical intervention is required in symptomatic patient irrespective of its size [2].

\section{Case Presentation}

A 39-year-old man presented to our otolaryngology outpatient clinic after being referred by Neurosurgery for an incidental finding of a nasopharyngeal mass on MRI. The patient initially presented to Neurosurgery with a 2-year history of pain in the neck and shoulder associated with stiffness. MRI of cervical spine done at the time showed C5C6 disc prolapse. Anterior Cervical Discectomy and Fusion was performed. Postoperative MRI revealed the incidental finding of a multilocular posterior nasopharyngeal cyst of about $2 \times 2$ centimeters (Figures $1 \& 2$ ).

During initial presentation to our outpatient clinic, the patient gave history of headache, especially during rotational movement, dizziness, halitosis, and neck pain and stiffness of 2 years duration. He denied any history of snoring, nasal obstruction, dysphagia, odenophagia, epistaxis, post-nasal drip, fever, or weight loss. He also denied ear symptoms, including unilateral or bilateral hearing loss or sensation of ear block.

He was previously healthy with no past medical or surgical history except for the recent anterior Cervical Discectomy and Fusion. He is married, a heavy smoker. He has no history of drug allergy. There is no family history of the same complaint, any genetic, nor immunological disorders. 


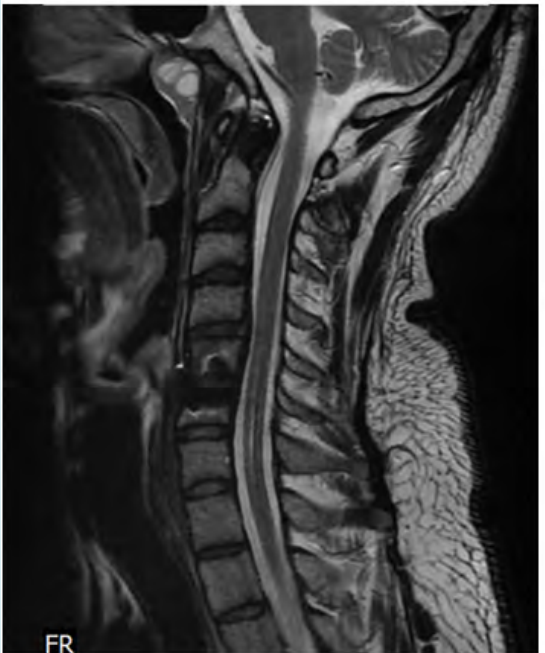

Figure 1

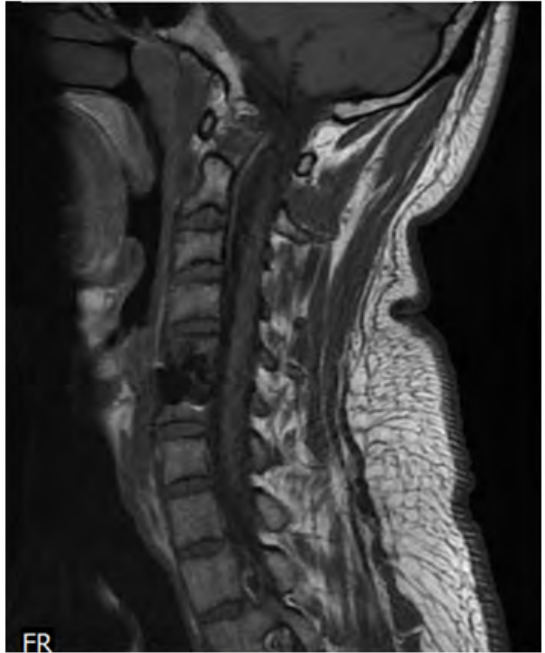

Figure 2

Figures 1 \& 2: Sagittal view of MRI cervical neck showing a hyperintense lesion in the posterior nasopharynx on T1 and T2 weighted imaging

On examination the patient was healthy looking, conscious, alert and oriented to time, place and people. His blood pressure and heart rate were within normal and she was afebrile. Examination of the nose, throat, paranasal sinuses, and tympanic membranes was normal. Tunning fork tests (Rinne and weber tests) were normal. There was no spontaneous nystagmus. His neurological examination was normal and cranial nerves were intact. There were no enlarged cervical lymph nodes. His full blood count, urea and electrolytes, fasting blood sugar, cholesterol and triglycerides were all within normal limits. Nasoendoscopy performed in the outpatient clinic confirmed the presence of a cyst in the posterior wall of the nasopharynx.

A decision was made to proceed with surgical intervention. He underwent endoscopic cystmarsupialization via a combined transnasal and transoral approach to the nasopharynx under general endotracheal anesthesia (Figures 3 \& 4).

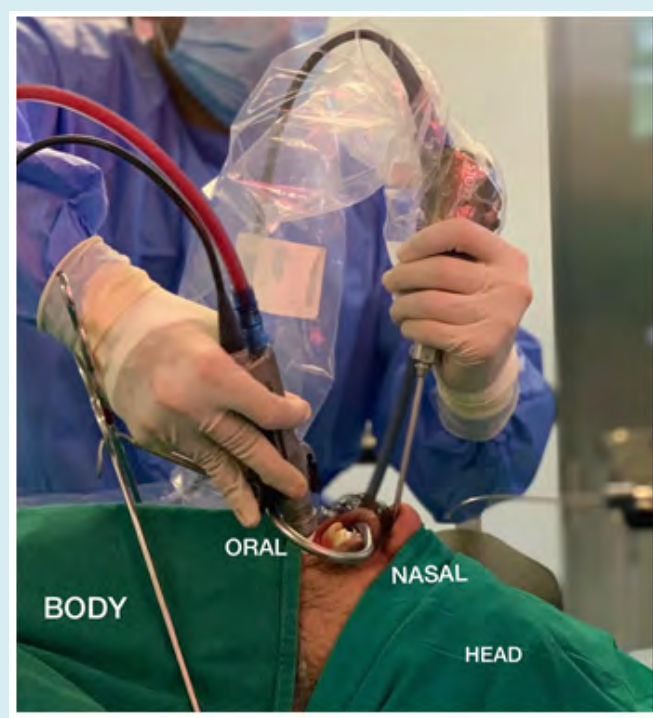

Figure 3

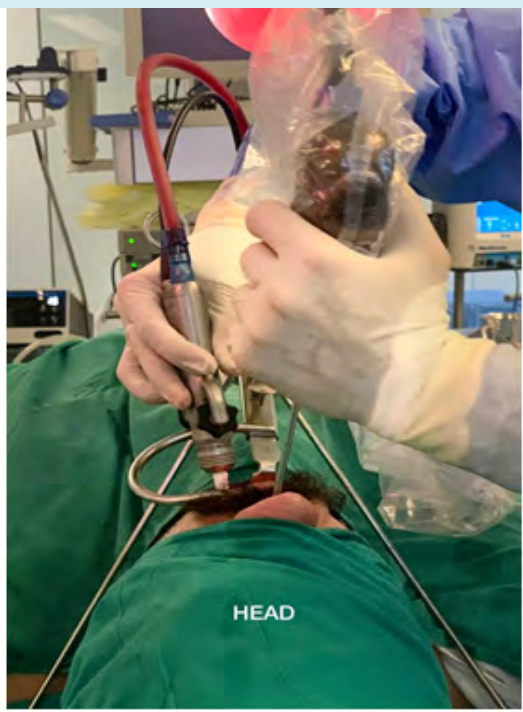

Figure 4

Figures 3 \& 4: Combined transnasal-transoral approach to the nasopharynx using a $60^{\circ}$ angle $3 \mathrm{~mm}$ Microdebrider ${ }^{\circledast}$ (Medtronic Xomed ${ }^{\circledR} \mathrm{Jacksonville}$ FL USA) guided by a $0^{\circ}$ rigid nasal endoscope. 


\section{Otolaryngology Open Access Journal}

Initially, Intraoperative endoscopic examination revealed a nasopharyngeal mass at the posterior nasopharyngeal wall. Guided by a $0^{\circ}$ rigid nasal endoscope, a transnasal opening of the cyst wall using sickle knife was initially done. Bleeding observed that was controlled by suction and insertion of packs inside the nasopharyngeal cyst. Packs then removed, and transnasal biopsies were taken and sent to histopathology. Marsupialization of the mass via a combined transnasal and transoral approach using a $60^{\circ}$ angle $3 \mathrm{~mm}$ Microdebrider ${ }^{\circledR}$ (Medtronic Xomed ${ }^{\circledR}$ Jacksonville, FL USA) guided by a $0^{\circ}$ rigid nasal endoscope was done. Marsupialization of the nasopharyngeal portion of the cyst wall was performed transnasally and oropharyngeal remnants of the cyst were accessed transorally using $0^{\circ}$ rigid nasal endoscope. Minimal bleeding was observed during the procedure and was controlled by packing and suction cautery introduced transorally and guided by a $0^{\circ}$ rigid nasal endoscope (Figure 5). The patient was given dexamethasone $8 \mathrm{mg}$ IV intraoperatively and till one day after surgery along with analgesics. The procedure lasted two hours. He was discharged the next morning on regular follow-up visits. Mucosal healing was observed during his serial follow-up visits. Histopathology report revealed a respiratory epithelium- lined cyst. With radiological and histopathological findings, the diagnosis of Thornwaldt cyst was made.

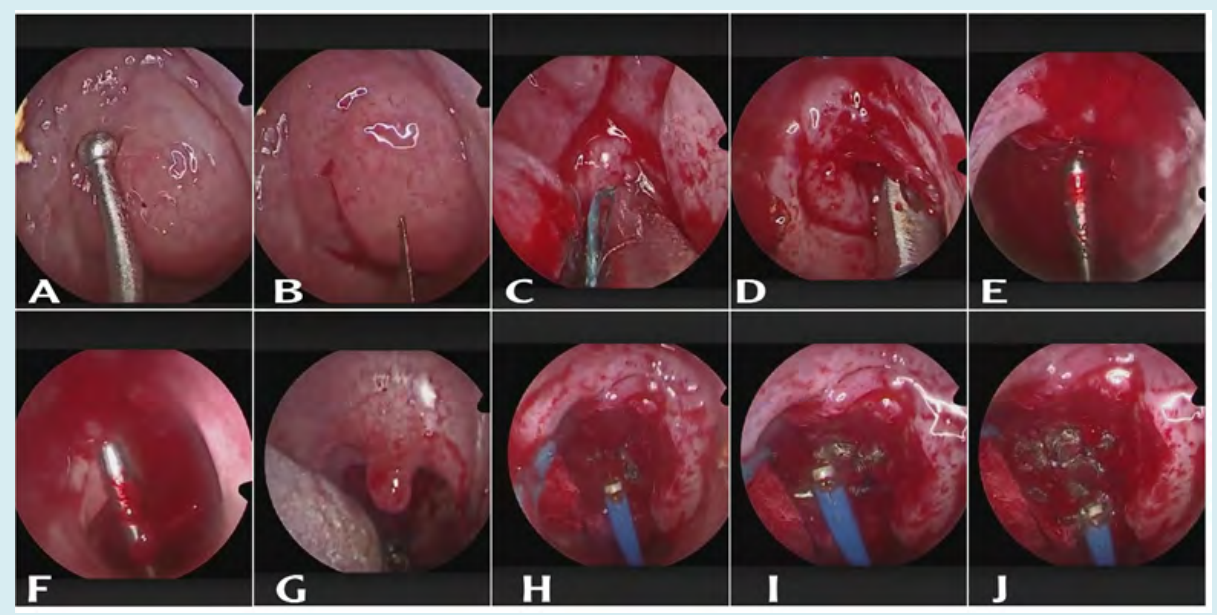

Figure 5: A. Intraoperative endoscopic examination showing the nasopharyngeal mass B. Opening of cyst wall with Sickle knife C. Pack inserted in the nasopharyngeal cyst for bleeding control D. Multiple biopsies taken for histopathology E,F. Marsupialization of the mass via a combined transnasal and transoral approach $\mathrm{G}$. transoral examination and introduction of suction cautery for bleeding control. H, I, J. Suction cautery using combined transnasal and transoral approach.

The combined transnasal-transoral surgical approach provided optimal visualization of and access to the nasopharynx, precise excision of delicate cyst walls, and less traumatic intranasal instrument manipulation.

\section{Discussion}

A Thornwaldt cyst is a benign developmental cyst that develops as a recess, called Thornwaldt's bursa, formed by the remnants of the notochord tissue with pharyngeal respiratory epithelium along the midline wall of the nasopharynx [3]. It is classified based on drainage as one of two categories: cystic and crusting. The cystic type is defined by cyst formation due to obstruction of the drainage pathway while the crusting type is defined by spontaneous drainage into the nasopharynx [4]. The peak age of incidence is between the ages of $15-30$ [5]. There is no gender preponderance.
The majority of these cysts tend to be asymptomatic. They are either discovered incidentally through imaging modalities such as CT scan or MRI or when patients present with symptoms. The signs of the cyst are defined as proximal and associated symptoms. Proximal symptoms are characterized by nasopharyngeal inflammation (hyperemia and hyperplasia in the nasal mucosa). On the other hand, associated symptoms include middle ear diseases due to obstruction of the Eustachian tube, granular pharyngitis, chronic laryngitis, bronchitis, bronchial asthma, cough because of laryngeal irritation, occipital headache, and cervical pain. Occipital headache occurs due to myalgia of the cervical muscles remaining under the protuberance of the occipital bone [3]. The presentation often depends on the location and size of the cyst. Symptoms include snoring, nasal obstruction and ear block or conductive hearing loss caused by eustachian tube dysfunction [6]. When a Thornwaldt's cyst becomes infected, it may present with halithosis, sore throat and occipital headaches [7]. When nasopharyngeal 
mass is encountered, Thornwaldt cyst, branchial cleft cyst, Rathke's pouch cyst, adenoid retention cyst, meningocele or meningoencephalocele, choanal polyp, sphenoid sinus mucocele, angiofibroma, nasopharyngeal carcinoma, and papillary thyroid cancer metastases should be considered in the differential diagnosis [3] (Table 1).

To diagnose a patient with Thorwaldt cyst, available investigations include nasoendoscopy, CT scan and MRI. Nasoendoscopy can be performed to visualize the cyst which appears as an encapsulated lesion commonly located in posterior midline in the superior recess of the nasopharynx [8]. Computed tomography (CT) scan demonstrates a well-defined midline low density cyst on the posterior nasopharyngeal wall. Magnetic resonance imaging (MRI) remains the gold-standard imaging modality in the diagnosis of Thornwaldt cysts. They appear as hyperintense masses on T1-weighted and T2-weighted images due to the high presence of proteins or due to haemorrhage or both (Table 1) [9].

\begin{tabular}{|c|c|c|}
\hline \multicolumn{3}{|c|}{ Characteristics of Nasopharyngeal cystic lesions } \\
\hline & Image & Characteristics \\
\hline Thornwaldt's cyst & $\begin{array}{l}\text { CT: solid mass MRI: T1 intermediate } \\
\text { to hyperintensity, } 12 \text { hyperintensity }\end{array}$ & $\begin{array}{l}\text { Congenital midline cyst, measuring a few } \mathrm{mm} \text { to } 12 \mathrm{~cm} \text {, } \\
\text { smooth surface, a small orifice may be seen [1] }\end{array}$ \\
\hline Branchial cleft cyst & $\begin{array}{l}\text { CT: solid mass MRI: T1 hyperinlensity } \\
\text { [6], T2 hyperintensity }\end{array}$ & $\begin{array}{c}\text { Congenital lateral cyst: in the region of the Eustachian } \\
\text { tube cushion [8] }\end{array}$ \\
\hline Rathke's pouch cyst & $\begin{array}{l}\text { CT: solid mass MRI: T1 hyperinlensity, } \\
\text { T2 hyperintensity }\end{array}$ & $\begin{array}{l}\text { Superior position, located inferior to the sella and } \\
\text { cephalad and ventral to the site of Thornwaldt's cyst [6] }\end{array}$ \\
\hline Adenoid retention cyst & $\begin{array}{l}\text { CT: solid mass MRI: T1 intermediate, } \\
\text { T2 hyperintensity }\end{array}$ & $\begin{array}{l}\text { Acquired midline or lateral cyst, usually small }(<5 \mathrm{~mm}) \\
\text { and multiple [2] }\end{array}$ \\
\hline $\begin{array}{l}\text { Meningpencephalocele } \\
\text { or meringocele }\end{array}$ & $\begin{array}{c}\text { CT: bony erosion MRI: T1 } \\
\text { intermediate [6], T2 hyperintensity }\end{array}$ & $\begin{array}{l}\text { Superior midline position, connected to the intracranial } \\
\text { tissues }\end{array}$ \\
\hline $\begin{array}{l}\text { Sphenoid sinus } \\
\text { mucocele }\end{array}$ & $\begin{array}{c}\text { CT: bony erosion MRI: T1 } \\
\text { intermediate, T2 hyperintensity }\end{array}$ & $\begin{array}{l}\text { Superior midline position, bone defectin the floor of the } \\
\text { sphenoid sinus [9] }\end{array}$ \\
\hline $\begin{array}{l}\text { Nasopharyngeal } \\
\text { carcinoma }\end{array}$ & $\begin{array}{l}\text { CT: solid mass, bony erosion MRI: T1 } \\
\text { intermediate, T2 hyperintensity }\end{array}$ & $\begin{array}{c}\text { Lateral position. irregular surface, and there may be } \\
\text { bleeding }\end{array}$ \\
\hline
\end{tabular}

Table 1: Differential diagnosis of nasopharyngeal cystic lesions and their characteristics on computed tomography (CT) and magnetic resonance imaging (MRI) [1].

Asymptomatic cysts require no intervention. However, symptomatic are managed surgically by excision or marsupialization [10]. In our case, although it's a rare presentation, cervical myalgia, headache, neck pain, and stiffness might be caused by the presence of the nasopharyngeal mass. Moreover, the patient presented with halitosis which indicate the presence of infection. The combined transnasal-transoral surgical approach provided optimal visualization of and access to the nasopharynx, precise excision of delicate cyst walls, and less traumatic intranasal instrument manipulation.

\section{Conclusion}

In summary, this case is unique as thorwaldt cysts are relatively uncommon. They are usually found incidentally on MRI. Thornwaldt cysts require a unique approach to prevent misdiagnosis and ensure adequate management. The combined endoscopic approach technique allows minimal tissue displacement and provides adequate visualization.

\section{References}

1. Lin JH, Tai CF, Lee KW, Ho KY, Kuo WR (2006) Huge Thornwaldt's Cyst: A Case Report. The Kaohsiung Journal of Medical Sciences 22(10): 524-528.

2. Baisakhiya N, Deshmukh P, Pawar V (2011) Tornwaldt Cyst: A Cause of Neck Pain and Stiffness. Indian J Otolaryngol Head Neck Surg 63(1): 147-148.

3. Ketenci I, Cihan MC, Doğan M, Akay E, Ünlü Y (2014) A Giant Thornwaldt Cyst: Case Report. Erciyes Med Journal 36(4): 170-173.

4. Miyahara H, Matsunaga T (1994) Tornwaldt's Disease. Acta oto-Laryngologica 114(517): 36-39.

5. Bakshi R (2001) A 25-Year-Old Man with Headaches.

6. Eloy P, Watelet JB, Hatert AS, Bertrand B (2006) Thornwaldt's cyst and surgery with powered instrumentation. B-ENT 2(3): 135-139. 


\section{Otolaryngology Open Access Journal}

7. Ng W, Sinnathuray A (2012) Nasopharyngeal (Tornwaldt's) Cyst: Rare Finding in a Habitual Snorer. Malays Fam Physician 7(2-3): 39-41.

8. Yanagisawa E, Yanagisawa K (1994) Endoscopic view of Thornwaldt cyst of the nasopharynx. Ear, Nose, \& Throat Journal 73(12): 884-885.
9. Ikushima I, Korogi Y, Makita O, Komohara Y, Kawano H, et al. (1999) MR imaging of Tornwaldt's cysts. American Journal of Roentgenology 172(6): 1663-1665.

10. Weissman JL (1992) Thornwaldt cysts. American Journal of Otolaryngology 13(6): 381-385. 